\title{
Ácidos tartárico e málico no mosto de uva em Bento Gonçalves-RS
}

\author{
Tartaric and malic acids in the must grapes of Bento Gonçalves-RS, Brazil
}

\author{
Luiz Antenor Rizzon ${ }^{I^{*}}$ Vânia Maria Ambrosi Sganzerla
}

\begin{abstract}
- NOTA -
RESUMO

Os ácidos tartárico e málico são os principais componentes responsáveis pela acidez do mosto da uva. Suas concentrações no mosto estão relacionadas com aspectos fisiológicos da maturação da uva, com os fatores naturais de clima e solo da região vitícola e com as práticas agronômicas da produção. A razão tartárico/málico é importante para definir a colheita da uva e direcionar o sistema de vinificação. $O$ objetivo do presente trabalho foi determinar os teores dos ácidos tartárico e málico e calcular a razão tartárico/málico dos

the tartaric/malic ratio in musts of principal grapes varieties used in the vinification in Bento Gonçalves-RS, Brazil. Eight one red grape musts were analysed: Cabernet Sauvignon, Cabernet Franc, Merlot and Isabel and 56 musts of white grapes: Chardonnay, Italic Riesling, Muscat and Niagara. Quantitative analysis was carried out by using HPLC. The values were submitted to analysis of mean comparison through the Tukey test. The results showed predominance of the tartaric acid in all musts analysed and lower level of two both acids in the american grape musts - Isabel and Niagara - compared with Vitis vinifera varieties.
\end{abstract} mostos de cultivares de videira usadas na vinificação em Bento Gonçalves-RS, na safra de 2004. Foram analisados 81 mostos de uvas tintas: Cabernet Sauvignon, Cabernet Franc, Merlot e Isabel, e 56 mostos de uvas brancas: Chardonnay, Riesling Itálico, Moscato e Niágara. As determinações foram efetuadas por cromatografia líquida de alta eficiência (CLAE). Os valores obtidos foram submetidos à análise de variância e ao teste de Tukey para comparação das médias. Os resultados evidenciaram predominância do ácido tartárico em relação ao málico, em todos os mostos, e teores mais baixos de ácido tartárico e málico nas uvas do grupo das americanas - Isabel e Niágara - em comparação com as cultivares de Vitis vinifera.

Palavras-chave: uva, composição química, ácidos orgânicos.

\section{ABSTRACT}

Tartaric and malic acids are the main components responsible for the ocidity of the grape must. The level is normally correlated with the physiological aspects of ripening grapes, with the preceding climate conditions, soil aspects and agronomic practice production. The tartaric / malic ratio is very important to determine the moment to harvest and to conduct the winemaking. The purpose of this work was to determine the concentration of tartaric and malic acids, and
Key words: grape, chemical composition, organic acids.

A acidez da uva na maturação é devida essencialmente aos ácidos tartárico, málico e cítrico, encontrados em todas as partes da videira (BLOUIN \& GUIMBERTEAU, 2000). O ácido tartárico da uva é o isomero $\mathrm{L}(+)$ encontrado em pequeno número de espécies vegetais, sendo a videira uma das poucas plantas onde ele está presente em quantidade elevada (PEYNAUD, 1947; CHAMPAGNOL, 1984; FAVAREL, 1994). É um ácido forte que interfere diretamente no $\mathrm{pH}$ do vinho e é relativamente resistente à respiração oxidativa. O teor de ácido tartárico no mosto varia de 3 a $9 \mathrm{~g} \mathrm{~L}^{-1}$, segundo a cultivar e as condições de produção da uva, especialmente a disponibilidade de água (BLOUIN \& GUIMBERTEAU, 2000). Para a mesma cultivar e para as mesmas condições de produção, as variações anuais são pequenas. O aumento do ácido

IEmpresa Brasileira de Pesquisa Agropecuária - Embrapa Uva e Vinho, 95700-000, Bento Gonçalves, RS, Brasil. E-mail: rizzon@cnpuv.embrapa.br. *Autor para correspondência. 
tartárico na uva não se reflete diretamente no vinho, já que o teor de potássio favorece a precipitação do tartarato ácido de potássio (PATO, 1999). Mesmo que o ácido tartárico seja sintetizado nas folhas novas, não foi constatada a influência do vigor e das práticas culturais no seu teor (RUFFNER, 1982; CHAMPAGNOL, 1984).

O ácido málico natural da uva é o isomero L(-) (PEYNAUD, 1947; CHAMPAGNOL, 1984; FAVAREL, 1994). É um dos ácidos orgânicos mais difundidos na natureza, predominando em grande número vegetais. É considerado um ácido fraco e pouco resistente à respiração oxidativa. Na videira, a síntese do ácido málico resulta de uma reação secundária da fotossíntese, ocorrendo principalmente nas folhas adultas da videira. Entretanto, pode ser sintetizado nos grãos em formação, até o momento do início da fase de maturação (RIBÉREAU-GAYON, 1968). No grão, uma parte do ácido málico provém da oxidação da glicose na respiração. Além disso, o ácido cítrico presente nas raízes da videira é precursor do ácido málico da folha e do grão.

O teor mais elevado ( 25 a $30 \mathrm{~g} \mathrm{~L}^{-1}$ ) de ácido málico no grão da uva é encontrado no início da maturação (PEYNAUD, 1947; RIBÉREAU-GAYON, 1968; RUFFNER, 1982; CHAMPAGNOL, 1984). Nesta fase, observa-se degradação, mais importante que a síntese, o que determina redução do teor de ácido málico, que será tanto mais rápida quanto mais elevada a temperatura. Entre os fatores que interferem no teor de ácido málico do mosto, destacam-se o vigor da videira e a disponibilidade de cátions, especialmente o potássio. A degradação do ácido málico é muito influenciada pela temperatura elevada (KLIEWER et al., 1967). As cultivares de videira não possuem a mesma capacidade de acumular e degradar o ácido málico na maturação. O ácido cítrico, assim como o málico, estão largamente difundidos na natureza, mas encontram-se em maior quantidade nas plantas cítricas e, em pequena quantidade, na uva.

Devido à importância dos ácidos tartárico e málico na determinação da qualidade da uva para vinificação e na definição do sistema de vinificação a ser adotado, realizou-se o presente trabalho com o objetivo de avaliar a composição desses ácidos nos mostos de Bento Gonçalves, na safra de 2004.

Os ácidos tartárico e málico foram analisados por cromatografia líquida de alta eficiência (CLAE), utilizando-se um cromatógrafo líquido PerkinElmer, operando em condição isocrática, com detector Diode Array e um injetor Rheodyne 7125 de $20 \mu \mathrm{L}$. A separação dos ácidos tartárico e málico foi realizada com coluna Varian MCH-NCAP-5 de $15 \mathrm{~cm}$ de comprimento e 4,6mm de diâmetro interno. O detector foi fixado no comprimento de onda de $212 \mathrm{~nm}$. Na diluição, utilizou-se um eluente constituído de água ultrapura, acidificada com ácido fosfórico a pH 2,5 (AUGUSTE, 1979). As amostras de mosto foram previamente diluídas a 10\% com água ultrapura, filtradas através de membrana de éster de celulose de $0,45 \mu \mathrm{m}$ e injetadas no aparelho. Quantidades conhecidas de uma solução padrão dos ácidos tartárico e málico foram dissolvidas em água e analisadas. As concentrações dos ácidos tartárico e málico foram obtidas através da relação entre a área dos picos dos ácidos da solução padrão, com a área dos picos das amostras dos mostos. Todas as análises foram feitas em triplicata. Foram analisados 81 mostos de uvas tintas da safra 2004, das cultivares Cabernet Sauvignon (13), Cabernet Franc (22), Merlot (30) e Isabel (16) e 56 mostos de uvas brancas, das cultivares Chardonnay (8), Riesling Itálico (10), Moscato (16) e Niágara (22). Os mostos foram coletados por ocasião do esmagamento da uva na Cooperativa Vitivinícola Aurora Ltda., de Bento Gonçalves, acondicionados em frascos de vidro e conduzidos para o Laboratório de Instrumentação da Embrapa Uva e Vinho, para as análises.

A partir dos teores dos ácidos málico e tartárico obtidos, foi calculada a razão tartárico/málico e efetuada a análise de variância, seguida pelo teste de Tukey para comparação das médias, a $1 \%$ de probabilidade de erro. O delineamento experimental utilizado foi o completamente casualizado, considerando a cultivar como tratamento.

Os teores de ácido tartárico, málico e a razão tartárico/málico dos mostos de cultivares de videira de Bento Gonçalves - RS, na safra de 2004, estão indicados na tabela 1 .

Foram constatados teores médios mais elevados de ácido tartárico nos mostos das cultivares de Vitis vinifera, exceto para a Moscato, que não apresentou diferença estatística significativa em relação à Niágara, que pertence, juntamente com a Isabel, à espécie de Vitis labrusca. Os teores médios de ácido tartárico detectados correspondem aos valores indicados para mostos de outras regiões vitícolas (PEYNAUD, 1947; KLIEWER et al., 1967; RICE, 1974; RUFFNER, 1982; BLOUIN \& GUIMBERTEAU, 2000)e com os mostos das cultivares Isabel, Cabernet Sauvignon e Cabernet Franc da Serra Gaúcha de outras safras vitícolas (GUERRA et al., 1992; RIZZON et al., 1998; RIZZON \& MIELE, 2002).

As cultivares de videiras do grupo das americanas se caracterizam por apresentar mostos com baixos teores de açúcar, mas com acidez total elevada e pH baixo (RICE, 1974). Ao contrário, no presente 
Tabela 1 - Teores dos ácidos tartárico e málico $\left(\mathrm{g} \mathrm{L}^{-1}\right)$ e razão tartárico/málico de mostos de cultivares de videira de Bento Gonçalves - RS. Safra 2004.

\begin{tabular}{|c|c|c|c|c|c|c|}
\hline \multirow[t]{2}{*}{ Cultivar } & \multicolumn{2}{|c|}{ Ácido tartárico } & \multicolumn{2}{|c|}{ Ácido málico } & \multicolumn{2}{|c|}{ Razão tartárico/málico } \\
\hline & $\begin{array}{l}\text { Intervalo de } \\
\text { confiança * }\end{array}$ & Média** & $\begin{array}{l}\text { Intervalo de } \\
\text { confiança }\end{array}$ & Média & $\begin{array}{l}\text { Intervalo de } \\
\text { confiança }\end{array}$ & Média \\
\hline Cabernet Sauvignon & $7,3-8,1$ & $7,7 \mathrm{a}$ & $4,6-7,3$ & $5,9 \mathrm{a}$ & $1,1-1,6$ & $1,4 \mathrm{~cd}$ \\
\hline Cabernet Franc & $7,1-7,6$ & $7,3 \mathrm{ab}$ & $3,4-4,6$ & $4,0 \mathrm{bc}$ & $1,7-2,2$ & $1,9 \mathrm{bc}$ \\
\hline Merlot & $7,3-8,0$ & $7,7 \mathrm{a}$ & $3,4-4,2$ & $3,8 \mathrm{c}$ & $1,9-2,4$ & $2,1 \mathrm{~b}$ \\
\hline Isabel & $3,8-4,8$ & $4,3 \mathrm{e}$ & $1,4-2,7$ & $2,0 \mathrm{~d}$ & $1,8-3,0$ & $2,4 \mathrm{~b}$ \\
\hline Chardonnay & $5,6-8,3$ & $6,9 \mathrm{ab}$ & $4,1-6,6$ & $5,4 \mathrm{ab}$ & $0,8-1,8$ & $1,3 \mathrm{~cd}$ \\
\hline Riesling Itálico & $5,9-7,1$ & 6,5 bc & $1,8-3,9$ & $2,9 \mathrm{~cd}$ & $1,5-3,6$ & $2,6 \mathrm{~b}$ \\
\hline Moscato & $4,7-6,7$ & $5,7 \mathrm{~cd}$ & $4,0-6,2$ & $5,1 \mathrm{ab}$ & $0,9-1,6$ & $1,2 \mathrm{~d}$ \\
\hline Niágara & $4,2-5,5$ & 4,9 de & $0,8-1,4$ & $1,1 \mathrm{~d}$ & $3,6-5,8$ & $4,7 \mathrm{a}$ \\
\hline
\end{tabular}

*Nível de probabilidade de erro do intervalo de confiança $1 \%$.

**Médias seguidas por letras distintas, na coluna, diferem entre si pelo teste de Tukey a 1\% de probabilidade de erro.

estudo, foi detectado menor teor de ácido tartárico no mosto da cultivar Isabel, seguido pela Niágara. Isto se deve, provavelmente, aos fatores naturais de clima e solo, que proporcionam maturação adequada para essas uvas na região vitícola da Serra Gaúcha. No entanto, mesmo que o mosto da cultivar Isabel apresente menor teor de ácido tartárico, os seus vinhos geralmente são mais ácidos, devido à menor participação dos cátions, especialmente o potássio, na salificação dos ácidos orgânicos (RIZZON \& MIELE, 2002).

Quanto ao ácido málico, foram detectados teores mais elevados nas cultivares de Vitis vinifera, Cabernet Sauvignon, Chardonnay, Moscato, Cabernet Franc e Merlot, que se diferenciaram estatisticamente das uvas do grupo das americanas - Niágara e Isabel. No entanto, a cultivar Riesling Itálico também apresentou teor baixo, não existindo diferença significativa com relação às uvas do grupo das americanas.

Quanto à razão ácido tartárico/málico, foi evidenciada maior proporção de ácido tartárico do que málico em todas as cultivares avaliadas, destacandose a Niágara com o valor mais elevado. Embora tenha apresentado o mais baixo valor da razão, a cultivar Moscato não se diferenciou estatistivamente da Chardonnay e da Cabernet Sauvignon. A predominância do ácido tartárico nos mostos estudados pressupõe condições meteorológicas favoráveis à maturação da uva na safra de 2004. Essa relação é um dos índices que avalia o grau de maturação da uva. No entanto, considerando que o ácido málico diminui de forma constante e de modo mais rápido que o tartárico, a determinação exclusiva do ácido málico fornece informações importantes para a maturação da uva de uma determinada região. Embora o teor de ácido málico seja uma característica varietal, ele é influenciado pelos fatores naturais, especialmente a insolação e o calor do período de maturação da uva (KLIEWER et al., 1967; RIBÉREAU-GAYON, 1968; CHAMPAGNOL, 1984; BLOUIN \& GUIMBERTEAU, 2000). Em princípio, um período de maturação mais ensolarado e com temperaturas mais elevadas determinam maior degradação do ácido málico, por meio da combustão respiratória e, por conseguinte, uvas menos ácidas e mais maduras.

Os teores de ácido tartárico e málico do mosto da uva fornecem informações importantes para a condução do processo fermentativo e para a caracterização dos vinhos de uma região vitícola. A razão ácido tartárico/málico é um indicativo do grau de maturação da uva, contribuindo para definir o momento da sua colheita.

Em suma, foi constatado uma predominância do ácido tartárico em comparação ao málico em todos os mostos analisados. As uvas do grupo das americanas (Isabel e Niágara) apresentaram mostos com teores mais baixos de ácido tartárico e málico em comparação com as cultivares de Vitis vinifera.

\section{REFERÊNCIAS}

AUGUSTE, M.H. Application de la chromatographie en phase liquide à haute pression à l'analyse des moûts et des vins. 1979. 135f. Tese (Doctorat en Oenologie, Ampélologie) - Université de Bordeaux II, Talence, France.

BLOUIN, J.; GUIMBERTEAU, G. Maturation et maturité des raisins. Bordeaux: Éditions Féret, 2000. 151p. 
CHAMPAGNOL, F. Élements de physiologie de la vigne et de viticulture generale. Montpellier: DEHAN, 1984. 351p.

FAVAREL, J.L. L'acidité tartrique et l'acidité: du moût au vin. In: LALLEMAND. La microbiologie des vins mousseux: la stabilisation des vins: mecanismes et evaluation. Toulouse, 1994. p.87-94.

GUERRA, C.C. et al. Evolução dos ácidos tartárico e málico durante a maturação de uvas tintas. Pesquisa Agropecuária Brasileira, Brasília, v.27, n.3, p.479-491, 1992.

KLIEWER, W.M. et al. Concentrations of tartaric acid, malic acid and their salts in Vitis vinifera grapes. American Journal of Enology and Viticulture, Davis, v.18, n.1, p.42-54, 1967.

PATO, M.A.S. Influência dos principais ácidos do vinho na acidez real $(\mathrm{pH})$. Ciência e Técnica Vitivinícola, Alcobaça, v.14, n.2, p.55-66, 1999.
PEYNAUD, E. Étude sur les acides organiques du raisin et du vin. Bulletin de l'OIV, Paris, v.20, n.191, p.34-51, 1947.

RIBÉREAU-GAYON, G. Étude des mecanismes de synthese et de transformation de l'acide malique, de l'acide tartrique et de l'acide citrique chez Vitis vinifera. Phytochemistry, Elmsford, v.7, n.9, p.1471-1482, 1968.

RICE, A.C. Chemistry of winemaking from native american grape varieties. In: WEBB, A.D. Chemistry of winemaking. Washington: American Chemical Society, 1974. p.88-115.

RIZZON, L.A.; MIELE, A. A acidez na vinificação em tinto das uvas Isabel, Cabernet Sauvignon e Cabernet Franc. Ciência Rural, Santa Maria, v.32, n.3, p.511-515, 2002.

RIZZON, L.A. et al. Evolução da acidez durante a vinificação de uvas tintas de três regiões vitícolas do Rio Grande do Sul. Ciência e Tecnologia de Alimentos, Campinas, v.18, n.2, p.179-183, 1998.

RUFFNER, H.P. Metabolism of tartaric and malic acids in Vitis. Vitis, Siebeldingeir, v.21, n.3, p.247-259, 1982. 